Technical Note

\title{
Determination of DQE as a quantitative assessment of detectors in digital mammography: Measurements and calculation in practice
}

\author{
Anna WYSOCKA-RABINa, ${ }^{\star}$, Magdalena DOBRZYŃSKAa ${ }^{a}$ Katarzyna PASICZ ${ }^{b}$, Witold SKRZYŃSKI ${ }^{b}$, \\ Ewa FABISZEWSKA \\ ${ }^{a}$ Particle Acceleration Physics and Technology Division, National Centre for Nuclear Research (NCNR), Poland \\ ${ }^{b}$ Medical Physics Department, Maria Sklodowska-Curie National Research Institute of Oncology (MSCNRIO), Poland \\ *E-mail address: anna.wysocka@ncbj.gov.pl
}

\begin{abstract}
Introduction: Advances in digital detector technology and methods of image presentation in digital mammography now offer the possibility of implementing mathematical assessment methods to quantitative image analysis. The aim of this work was to develop new software to simplify the application of the existing international standard for DQE in digital mammography and show in detail how it can be applied, using a Siemens Mammomat Inspiration as a model.

Material and methods: Consistent with the IEC standard a $2 \mathrm{~mm} \mathrm{Al}$ filter at the tube exit and images in DICOM format as raw data, without applying any additional post-processing were used. Measurements were performed for W/Rh anode/filter combination and different tube voltage values $(26 \div 34 \mathrm{kV})$ without any anti-scatter grid. To verify new software doses ranging from 20-600 $\mu \mathrm{Gy}$ were used in measurements. Exposure (air kerma) was measured using a calibrated radiation meter (Piranha Black 457, RTI Electronics AB, Sweden). MTF was determined, using an edge test device constructed specifically for this work.

Results: It has been demonstrated that with the new software the DQE can be measured with the accuracy required by the international standard IEC 62220-1-2. DQE has been presented as a function of spatial frequency for W/Rh anode/filter combination and different tube voltage.

Conclusions: New software was used successfully to analyze image quality parameters for the Siemens Mammomat Inspiration detector. This was done on the basis of an internationally accepted methodology. In the next step, mammographs with different detector types can be compared.
\end{abstract}

Key words: digital mammography; modulation transfer function; noise power spectra; detective quantum efficiency; X-ray.

\section{Introduction}

Successful mammography requires high-quality images at doses that are safe for patients. Significant improvements in mammography systems have been achieved with the introduction of active-matrix flat-panel detectors. Digital mammography (DM) offers many advantages over traditional film/screen systems. Factors such as faster imaging, reduced radiation doses, and options to adjust the display have led to digital devices gradually replacing conventional systems. According to data from the Polish Breast Cancer Prevention Programm $^{1}$, in 2016 , only $22 \%$ of mammography systems used in screening laboratories were fully digital (versus $45 \%$ film and $33 \%$ computed devices). By 2019, the proportion of digital devices had increased to $40 \%$.

In 2013, breast cancer represented $21.9 \%$ of newly diagnosed cancer cases in Poland and caused $13 \%$ of cancer-related deaths. ${ }^{2}$ The key to improving patient outcomes is to start treatment at the earliest possible stage of cancer, which is why screening tests are very important. High-quality images allow physicians to detect tissue changes (i.e., microcalcification) that are too small to detect during palpation.

Despite advances in digital mammographic devices, routine evaluation of image quality in Poland still relies on subjective visual assessment of phantom images. ${ }^{3}$ Furthermore, the diagnostic criteria outlined in Polish regulations are derived from recommendations published in 1999 by the American College of Radiology. 4 The methodology described in these recommendations was designed for screen-film mammography and is not suitable for DM. ${ }^{\mathbf{5}}$ Objective methods of image quality assessment using computer software for automated analysis of threshold contrast visibility have been proposed. Unfortunately, results have varied considerably for different software versions and different phantoms of the same type. ${ }^{6}$ For optimal assessment of imaging quality and detector parameters, quantitative image analysis needs to be conducted using truly objective and well-standardized methods. Advances in digital detector technology and methods of image presentation in DM 
now offer the possibility of implementing mathematical assessment methods.

Quantitative image analysis requires parameters that precisely describe the information received during the imaging process. These values are the modulation transfer function $(\mathrm{MTF})^{\mathbf{7 - 1 1}}$, noise power spectrum (NPS) $)^{\mathbf{1 2}-14}$, and detective quantum efficiency (DQE) $)^{\mathbf{1 5 - 2 1}}$ of the digital detector, all of which are well described in the literature. In a properly working system, these parameters should be constant in time, and their values should be more sensitive than the visual estimation of any small changes in the imaging system. The further advantage of quantitative image analysis is its objectivity.

In this study, measurements and calculations of MTF, NPS, and DQE for a digital detector in mammography were performed in accordance with the standards of the International Electrotechnical Commission (IEC 62220-1-2:2007). ${ }^{\mathbf{2 2}}$

The aim of this study was to use new software to simplify the application of the existing international standard for DQE in DM and show in detail how to use it. The results of measurements and determination of the MTF, NPS, and DQE using a Siemens Mammomat Inspiration digital mammography system are presented. The studies were performed at the Maria Sklodowska-Curie National Research Institute of Oncology (MSCNRIO) in Warsaw, Poland using specially developed Python-based software to calculate the DQE*. These findings may be of particular value to readers who are new to DQE calculations.

\section{Materials and methods}

This section describes the equipment used to perform measurements and the steps that were applied to measure and calculate the DQE using new software developed specifically for this purpose.

\section{Equipment}

The DQE was determined using a Siemens Mammomat Inspiration system. The detector for this mammography system has a layer of amorphous selenium and an amorphous silicon thin-film transistor matrix readout with a pixel size of $85 \mu \mathrm{m}$. The system is equipped with an automatic exposure control (AEC) that can set exposure parameters (tube load in milliampere-seconds - mAs) based on breast size and composition. This feature enables optimal exposure to obtain the best quality image while keeping the patient dose as low as possible. Additionally, the AEC has a special mode called "OPDOSE" that recommends specific anode/filter combinations and $\mathrm{kV}$ settings based on the compressed breast thickness. We used a $2 \mathrm{~mm} \mathrm{Al} \mathrm{filter} \mathrm{at} \mathrm{the} \mathrm{tube} \mathrm{exit,} \mathrm{which} \mathrm{is} \mathrm{consistent} \mathrm{with}$ the IEC standard ${ }^{22}$ that recommends the addition of aluminum filtration. System operations were performed using settings that permitted the acquisition of images in Digital Imaging and Communications in Medicine (DICOM) format as raw data, without applying any additional post-processing. Measurements were performed for the $\mathrm{W} / \mathrm{Rh}$ anode/filter combination and different tube voltages ranging from 26 to $34 \mathrm{kV}$ without an antiscatter grid. This combination is used for most examinations in the MSCNRIO and is recommended by the manufacturer. To verify the new software, air kerma at detector entrance (KAD) values ranging from 20 to $600 \mu \mathrm{Gy}$ were used in the measurements (as shown in Table 1).

Table 1. Tube loading settings (mAs) and corresponding KAD values

\begin{tabular}{|c|c|c|c|c|c|c|}
\hline Tube voltage $[\mathrm{kV}]$ & & & & & & \\
\hline 26 & 6.3 & 12.5 & 25 & 36 & 50 & 100 \\
\hline 30 & 6.3 & 12.5 & 20 & 25 & 50 & 100 \\
\hline 34 & 2.5 & 6.3 & 11 & 12 & 25 & 50 \\
\hline Tube voltage [kV] & & & KA & Gy] & & \\
\hline 26 & 16 & 31 & 64 & 92 & 128 & 256 \\
\hline 30 & 26 & 52 & 84 & 105 & 210 & 419 \\
\hline 34 & 14 & 38 & 67 & 77 & 155 & 311 \\
\hline
\end{tabular}

\section{Software}

The new software that was developed to calculate the DQE is fully compliant with the requirements of the IEC standard. ${ }^{\mathbf{2 2}}$ The code was implemented in Python 3.7 language with a userfriendly graphic interface and several additional features to enhance ease of use. Its step-by-step structure guides the user through the process of calculating the DQE components: signal transfer property (STP), NPS, and MTF. Raw DICOM files are input according to the steps recommended by the IEC. The calculation procedure is automated and requires minimal user intervention. The results are immediately displayed in diagram form, and complete output data are exported to a commaseparated values (.csv) file. Further details on the calculations are described below.

\section{System response function}

The first step of image acquisition was to determine the linearity of the detector response, expressed as the relationship between the pixel value and the exposure.

The exposure (air kerma) was measured using a calibrated radiation meter (Piranha Black 457, RTI Electronics AB, Sweden) as a function of the tube load. A radiation meter was placed on the breast support table at the reference point. A geometry correction factor of the measured air kerma was introduced because exposure measurements should be performed at the entrance surface of the image detector.

Image registration was performed for the same tube load values for which the air kerma was measured. The dependency between the mean pixel value and the air kerma was fitted to a linear function. Fit-results fulfilled the requirement of $R^{2} \geq 0.99$ (where $R^{2}$ is the coefficient of determination). In the next step, this dependency was recalculated for photon fluence instead of air kerma, to establish the conversion function. Subsequently, the inverse conversion function was obtained, and this was used to linearize image data for the MTF and NPS calculations.

*Software freely available via email: magdalena.dobrzynska@ncbj.gov.pl 


\section{Edge test device}

Spatial resolution was characterized by evaluating the presampling MTF using an edge test device as shown in Figure 1a that was constructed and produced specifically for this study. Its quality was confirmed using an electron microscope. The edge test device is a $1 \mathrm{~mm}$ thick stainless-steel plate as recommended in IEC 62220-1-2:2007, ${ }^{22}$ with dimensions of $6 \times 12 \mathrm{~cm}^{2}$ and a polished edge perpendicular to the plate. The angle of the edge is $2^{\circ}$.

\section{Measurement and determination of MTF}

The MTF is a basic, objective, quantitative measure of an imaging system. It describes the system's capability to transfer object contrast to an image and decrease the amplitude of a signal as a function of spatial frequency. ${ }^{23}$ Therefore, the MTF can show the limits of an imaging device's ability to reproduce fine objects.

The procedure for calculating the MTF was implemented in the software. First, the oversampled edge spread function (ESF) as shown in Figure 1b, was determined based on the linearized data from the edge images in Figure 1a. Based on the angle between the test plate and rows (or columns) of the detector's pixels, the calculation area (Figure 1a marked in red) was divided into smaller calculation windows. From each window, an ESF was created based on the sub-pixel method. ${ }^{24}$ The line spread function (LSF) was calculated as a derivative of the ESF, and the MTF was calculated as a fast Fourier transform of the $\mathrm{LSF}^{25}$ In the next step, the MTF was normalized to its value at zero spatial frequency. All these steps were performed twice and applied to two images in which the edge was placed parallel to the chest wall side of the detector (perpendicular calculation direction: shown in Figure 1a in the area marked in red) to create $M T F_{\mathrm{X}}$ and perpendicular to the chest wall side of the detector in the parallel calculation direction $\left(M T F_{\mathrm{Y}}\right)$.

\section{Measurement and determination of output NPS}

The NPS in a spatial frequency domain is defined as the variance in the stochastic signal for each frequency bin. ${ }^{26}$ The major component of this signal is the quantum noise, with minor contributing factors including sources such as the detector construction and material. Thus, the NPS is a metric that represents the noise content in the obtained radiographic images. In this study, the NPS was determined from flat panel images, with an irradiated area of approximately $100 \mathrm{~mm} \times 100 \mathrm{~mm}$. The center of this area was located $60 \mathrm{~mm}$ from the center of the chest wall side of the detector, in conformity with IEC recommendations. To perform the NPS calculations, an area of $50 \mathrm{~mm} \times 50 \mathrm{~mm}$ was placed at the center of the irradiated square and divided into $256 \times 256$ pixel areas called regions of interest (ROIs). Linearized data from 12 images were used for the calculation to ensure 4 million pixels for analysis.

According to the IEC 62220-1-2:2007 standard, $^{\mathbf{2 2}}$ the frequency-dependent NPS $W_{\text {out }}$ was determined as:

$W_{\text {out }}\left(u_{n}, v_{k}\right)=\frac{\Delta x \Delta y}{M \times 256 \times 256} \sum_{m=1}^{M} \mid \sum_{i=1}^{256} \sum_{j=1}^{256}\left(I\left(x_{i}, y_{j}\right)-\right.$

$\left.S\left(x_{i}, y_{j}\right)\right)\left.\exp \left(-2 \pi i\left(u_{n} x_{i}+v_{k} y_{j}\right)\right)\right|^{2}$

Eq. 1

where

$x, y$ is the distance between the pixel centers in the horizontal and vertical directions, respectively;

$M$ is the total number of ROIs;

$I\left(\mathrm{x}_{i}, \mathrm{y}_{j}\right)$ is the linearized data; and

$S\left(x_{i}, y_{i}\right)$ is the optionally fitted two-dimensional polynomial.

To achieve a one-dimensional NPS from the two-dimensional result of Equation ), data from 14 rows (or columns) around the axis were averaged (excluding the axis itself). (a)

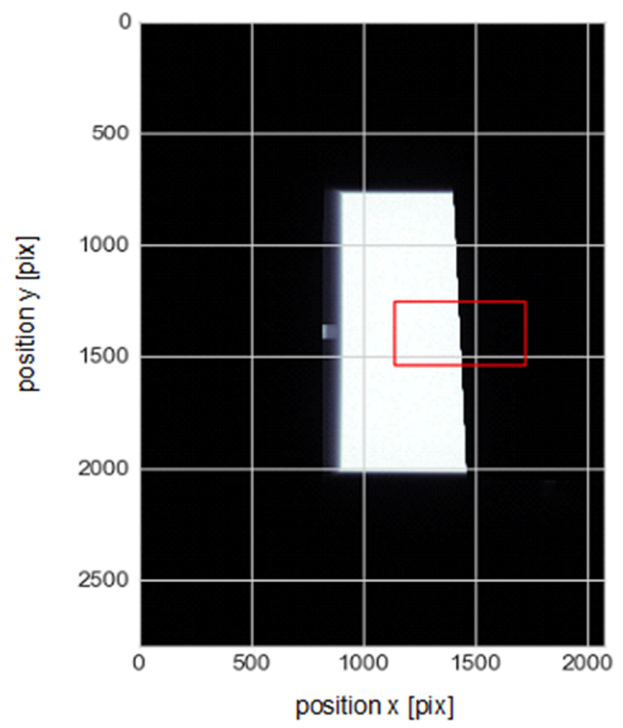

(b)

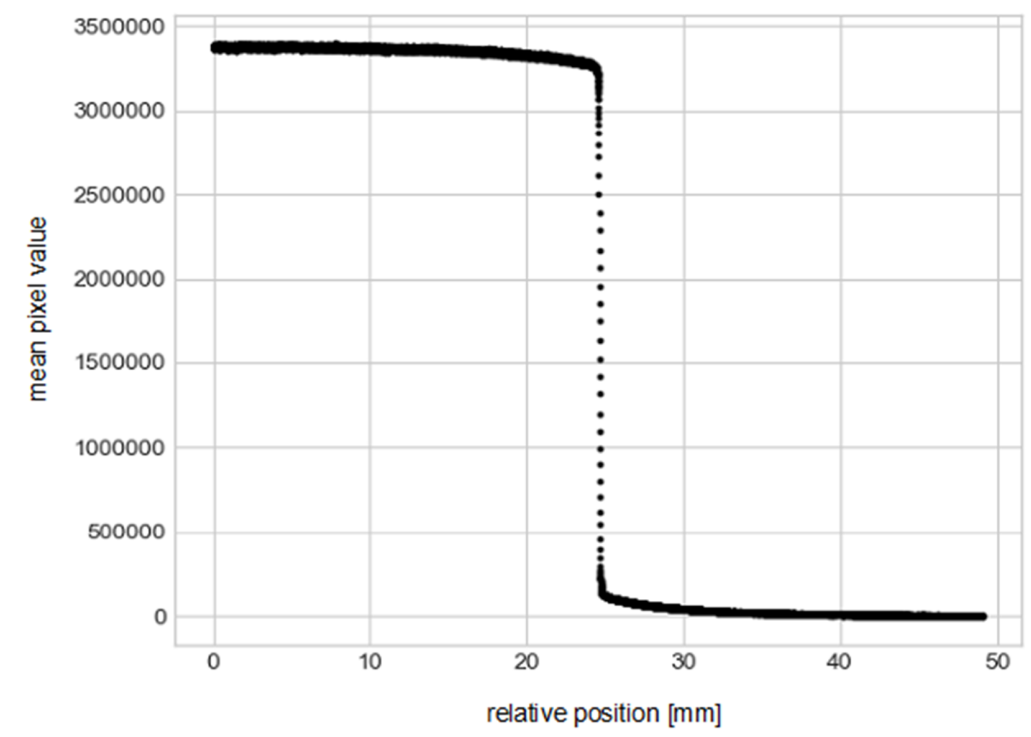

Figure 1: (a) Image of the edge test device, and (b) oversampled edge spread function (ESF) measured in the red-marked area shown in (a) 


\section{DQE calculation implemented in software}

The DQE describes a detector's capacity to convert an incident $\mathrm{X}$-ray into a radiographic image, based on an imaging system's signal-to-noise ratio (SNR). However, it should be noted that the DQE does not consider the influence of scattered radiation, focal spot blur, or an anti-scatter grid.

According to IEC 62220-1-2:2007 standard, ${ }^{22}$ the working equation for the determination of the spatial frequencydependent DQE is

$D Q E(u, v)=\operatorname{MTF}^{2}(u, v) \frac{W_{\text {in }}(u, v)}{W_{\text {out }}(u, v)}$

$\operatorname{MTF}(u, v)$ is the pre-sampling MTF of the detector in a digital Xray imaging device;

$W_{\text {in }}(u, v)$ is the input NPS of the radiation field at the detector surface, defined as the product of the measured KAD and the squared SNR per air kerma $\left(S N R_{\text {in }}^{2}\right)$;

$W_{\text {out }}(u, v)$ is the NPS $\left(N P S_{\text {out }}\right)$ at the output of the digital X-ray imaging device; and

$u, v$ are spatial frequencies.

The $S N R_{\text {in }}{ }^{2}$ values for several beam qualities are specified in Table 2 of the IEC standard. ${ }^{22} S N R_{\text {in }}{ }^{2}$ values for other beam qualities, specified in Table 2 of the current study, were calculated with the online tool for the simulation of X-ray spectra. $^{27}$

Table 2. $S N R_{\mathrm{in}}{ }^{2}$ values used in the calculations

\begin{tabular}{ccc}
\hline $\begin{array}{c}\text { Anode/filter } \\
\text { combination }\end{array}$ & Tube voltage $[\mathbf{k V}]$ & $\mathbf{S N R}_{\mathbf{i n}}{ }^{\mathbf{2}}\left[\mathbf{1} /\left(\mathbf{m m}^{\mathbf{2}} \boldsymbol{\mu G} \mathbf{G}\right)\right]$ \\
\hline & 26 & 5800 \\
28 & $5975^{*}$ \\
$\mathrm{~W} / \mathrm{Rh}$ & 30 & 6179 \\
& 32 & 6483 \\
& 34 & 6898 \\
\hline \hline
\end{tabular}

* Value taken from the IEC standard ${ }^{22}$

\section{DQE uncertainty}

The IEC standard ${ }^{22}$ states that uncertainty $\left(u_{D Q E}\right)$ should be calculated using the basic DQE Equation 2, based on instructions in Guides in Metrology. ${ }^{28}$ Thus, the relative uncertainty can be stated as:

$u_{D Q E}=\sqrt{\left(2 u_{M T F}\right)^{2}+\left(u_{W_{\text {in }}}\right)^{2}+\left(u_{W_{\text {out }}}\right)^{2}}$

The uncertainty of the MTF $\left(u_{\mathrm{MTF}}\right.$ ) for frequencies up to the Nyquist limit depends strictly on the number of lines in the window used in the calculation. ${ }^{29}$ Because this number depends on the angle of the test plate, uncertainty takes values in the range of 1.25 to $2.5 \%$. The uncertainty of $W_{\text {in }}$ in this study is less than $2.9 \%$. It depends on the accuracy of the air kerma detector device and calculation of distances: source to image detector, and source to air kerma detector. ${ }^{30,31}$

As described in $^{32}$ the uncertainty of the NPS can be calculated as:

$u_{W_{\text {out }}}=\frac{1}{\sqrt{\text { M×row } \times \text { bin }}}$

Eq. 4

where

$M$ is the total number of ROIs;

row is the number of rows used to calculate the one-dimensional NPS (14 according to IEC standard ${ }^{22}$ ); and

bin is the product of the resolution and the reported interval of the NPS spatial frequency.

$W_{\text {out }}$ uncertainty is approximately $0.7 \%$ for all calculation results in this study.

In conclusion, the relative DQE uncertainty $u_{D Q E}< \pm 10 \%$ (with coverage factor $k=2$ ), which is less than the value required in the IEC standard. ${ }^{22}$

\section{Results}

All results have been obtained using a W/Rh anode/filter combination. The STPs for different voltages are shown in Figure 2.

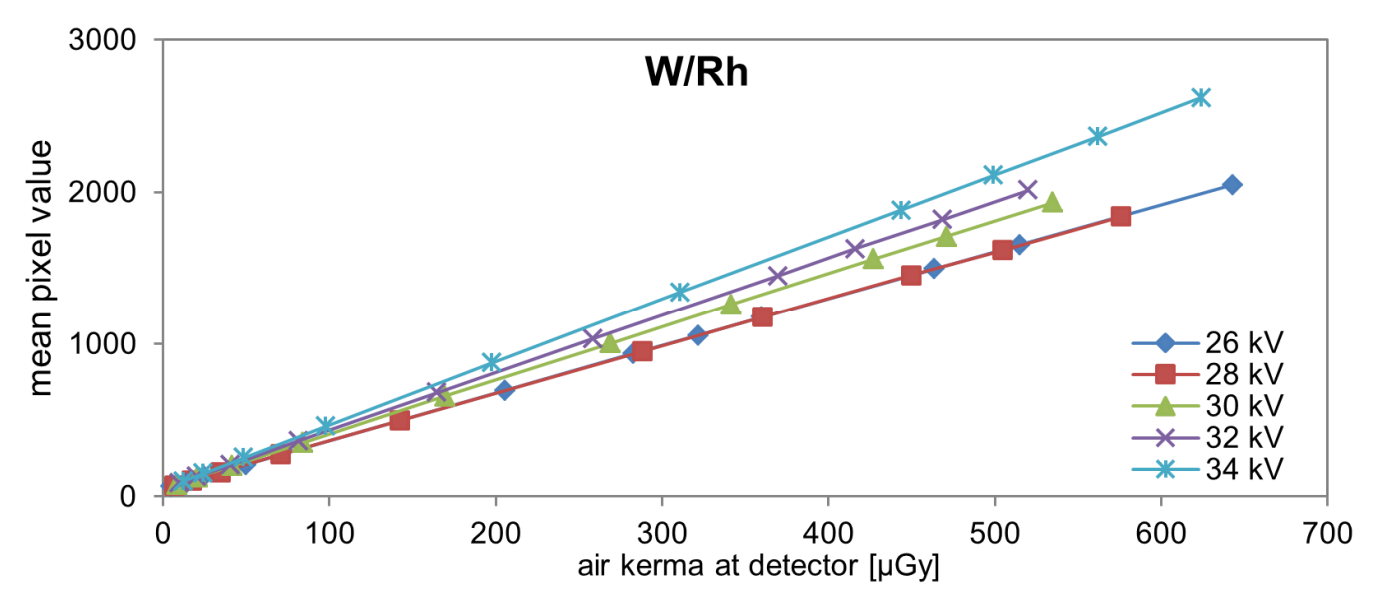

Figure 2. STPs of a W/Rh anode/filter combination for different voltages. 


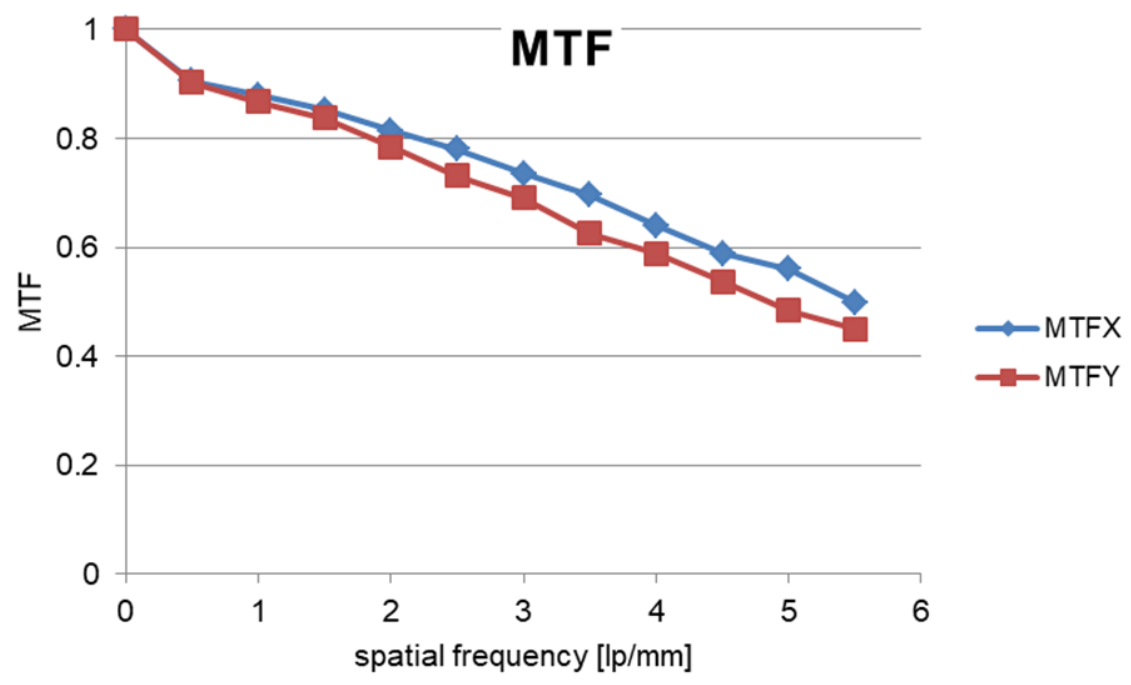

Figure 3. MTF for different directions for a W/Rh anode/filter combination at $30 \mathrm{kV}$ and $84 \mu \mathrm{Gy}$.
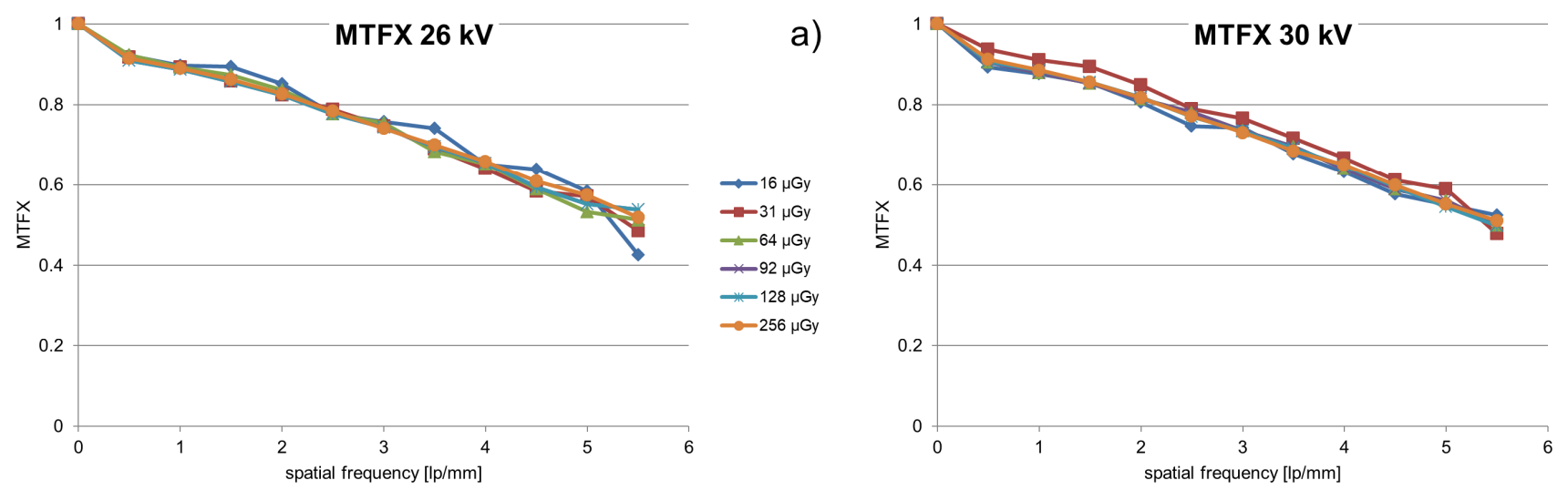

b)
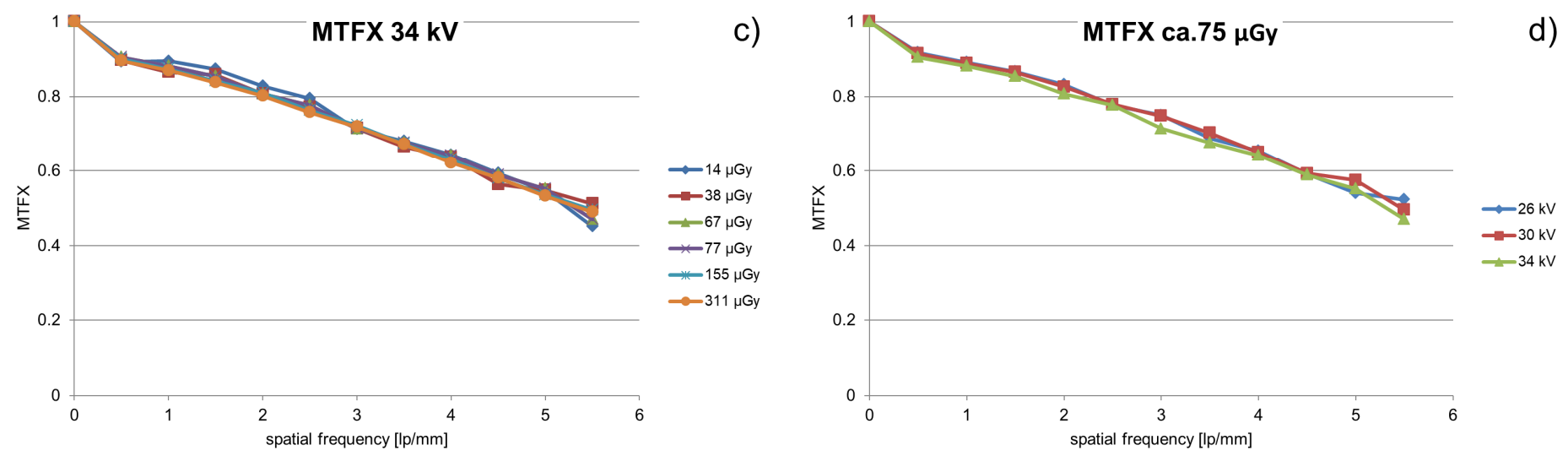

Figure 4. MTF (MTF uncertainty < 2.5\%) in x direction for a W/Rh anode/filter combination: for different $\mathrm{KAD}$ at (a) $26 \mathrm{kV}$, (b) $30 \mathrm{kV}$, and (c) $34 \mathrm{kV}$; and d) for different tube voltages at approximately $75 \mu \mathrm{Gy}$

Figure 3 shows the MTF for different calculation directions. Figure 4 shows the MTF values as a function of spatial frequency at different exposure levels and tube voltages. 


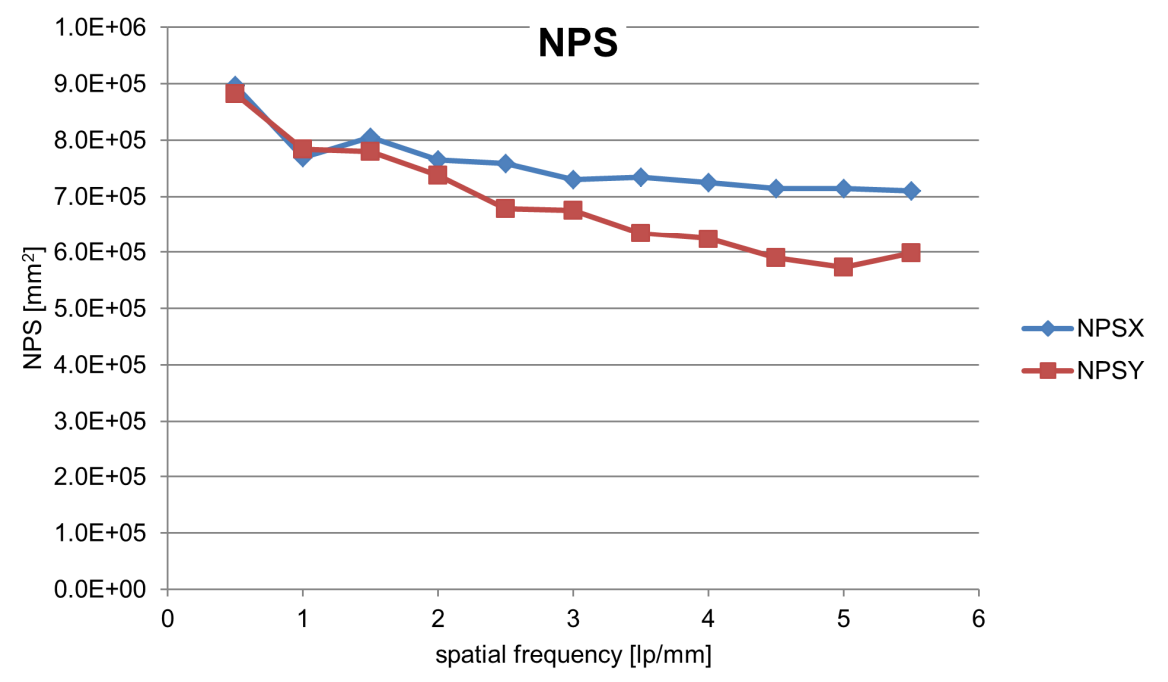

Figure 5. NPS for different directions for a W/Rh anode/filter combination at $30 \mathrm{kV}$ and $84 \mu \mathrm{Gy}$
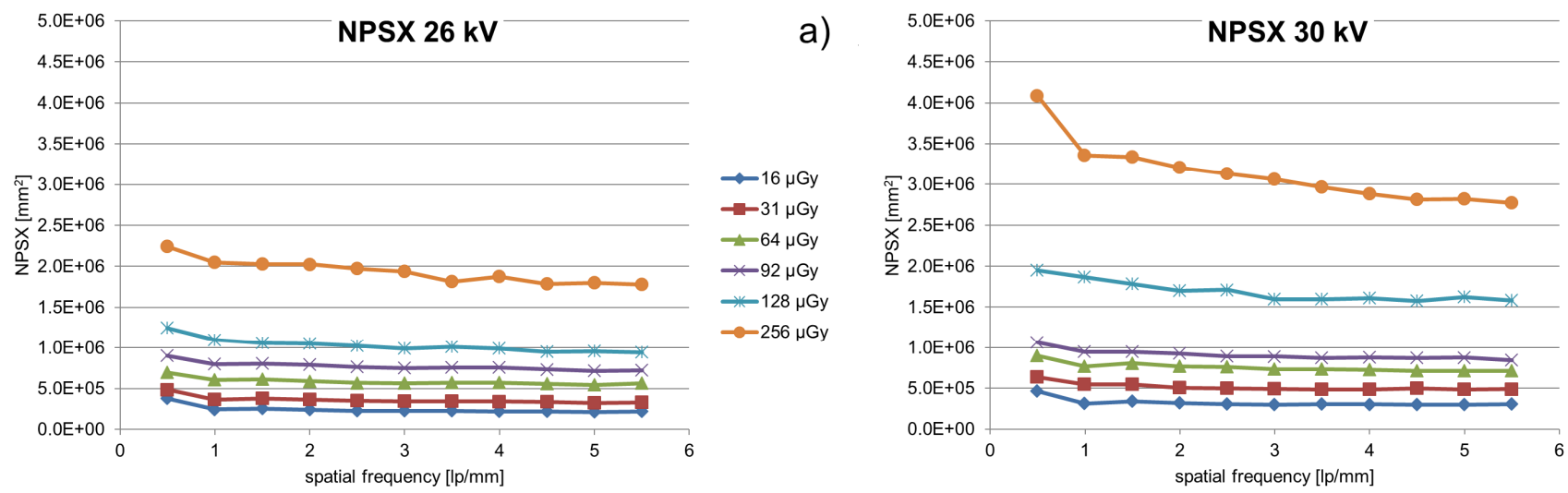

b)
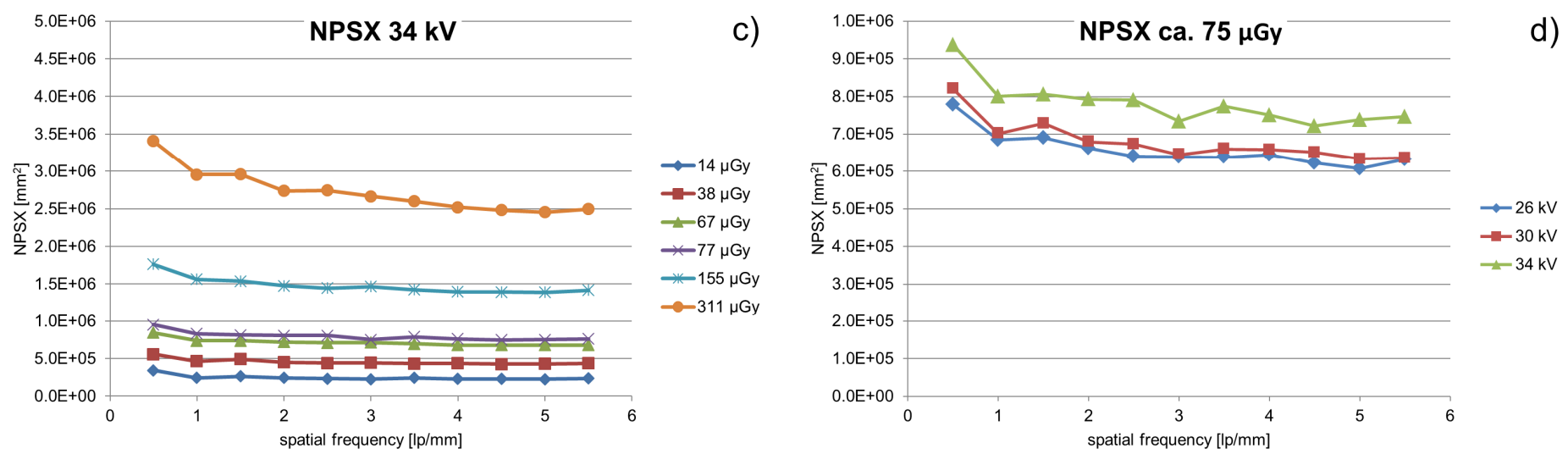

Figure 6. The NPS (NPS uncertainty $<1 \%$ ) in the $x$ direction for a W/Rh anode/filter combination: for different KAD at (a) $26 \mathrm{kV}$, (b) $30 \mathrm{kV}$, and (c) $34 \mathrm{kV}$; and (d) for different tube voltages at approximately $75 \mu \mathrm{Gy}$

Figure 5 shows the calculated NPS in different directions. Figure 6 shows the NPS values as a function of the spatial frequency at different exposure levels and tube voltages. 


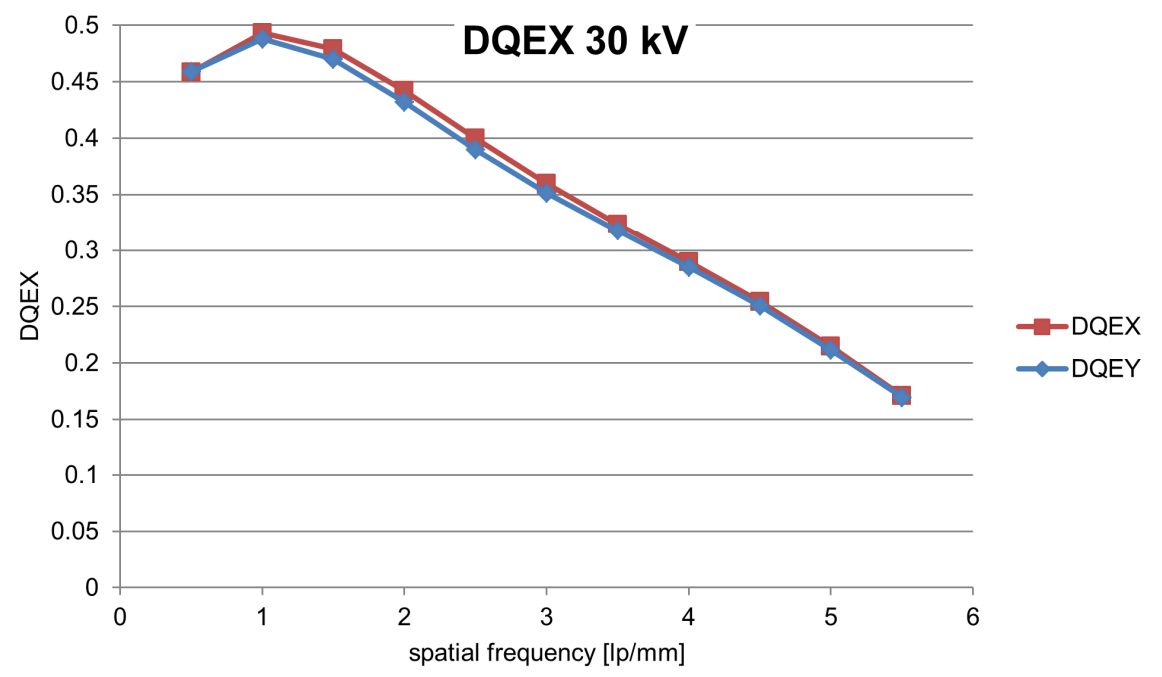

Figure 7. DQE for different directions for a W/Rh anode/filter combination at $30 \mathrm{kV}$ and $84 \mu \mathrm{Gy}$
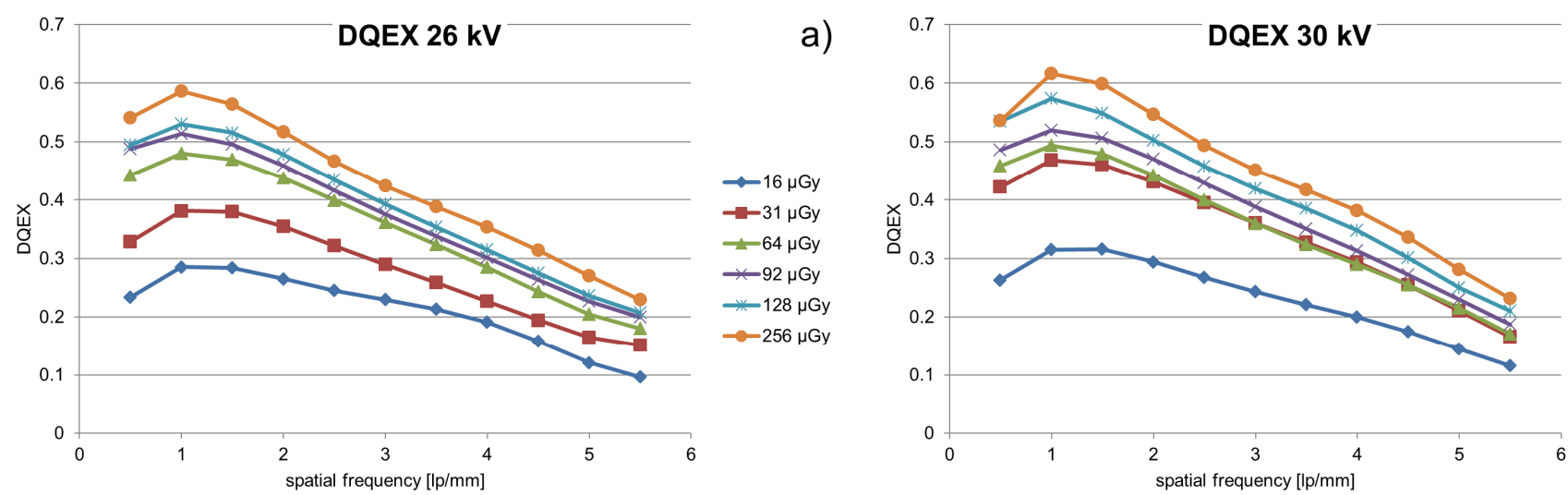

b)
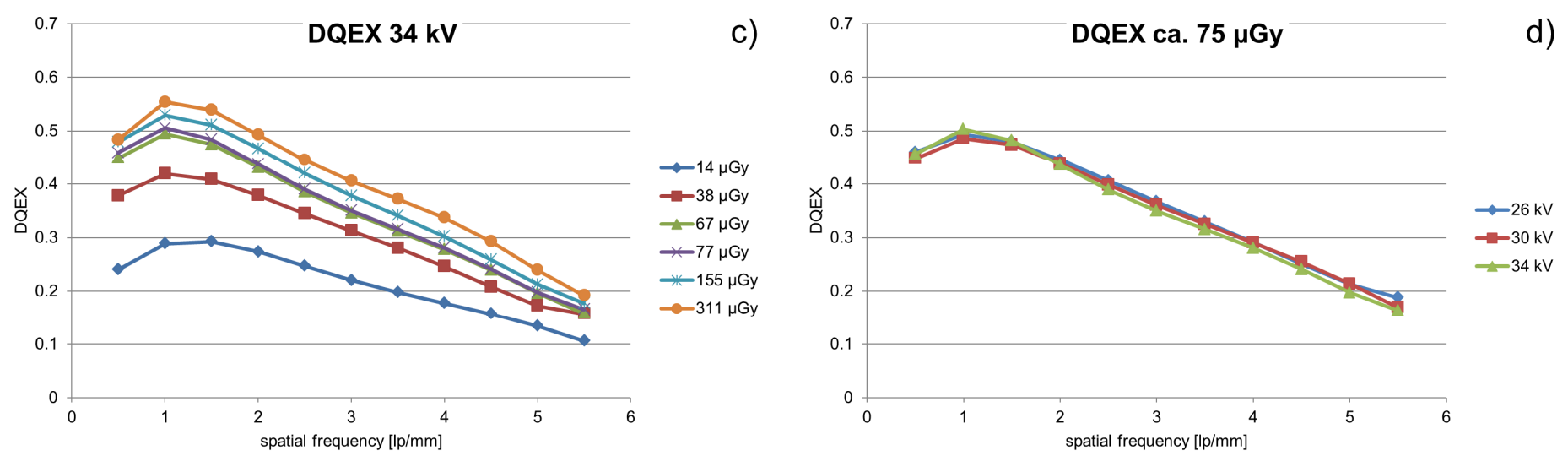

Figure 8. DQE (DQE uncertainty < $10 \%$ ) in the $x$ direction for a W/Rh anode/filter combination: for different $\mathrm{KAD}$ at (a) $26 \mathrm{kV}$, (b) $30 \mathrm{kV}$, and (c) $34 \mathrm{kV}$; and d) for different voltages at approximately $75 \mu \mathrm{Gy}$

Figures 7 and $\mathbf{8}$ show examples of DQE values as a function of the spatial frequency at different exposure levels and calculation directions. In this study, all DQE data obtained from our software were fit to the 5 th degree polynomial. 


\section{Discussion}

The STPs depend on the tube voltage (Figure 2). The relationship between the mean pixel value and KAD is linear, with correlation coefficients greater than 0.99 in all cases. The STP study demonstrated a direct relationship between the slope and beam quality, with a higher slope corresponding to the harder spectrum. When the spectrum hardness increased, a smaller air kerma was needed to produce the same pixel value.

The MTF values show a marked directional dependence (Figure 3). The MTF is higher in the perpendicular direction, which is consistent with the observations of other authors. ${ }^{33}$ The MTF is not affected by the KAD as shown in Figures $\mathbf{4 a}$ to $\mathbf{4 c}$, or the tube voltage in Figure 4d. The results obtained for different exposure parameters were essentially the same within the measurement uncertainty. In addition, a low-frequency drop of the MTF value between 0 and $0.5 \mathrm{lp} / \mathrm{mm}$ frequency was observed, which is a characteristic of Se-based detectors and primarily caused by backscatter, as others have observed..$^{34}$

The NPS shows a strong directional dependence with higher values in the perpendicular plane and a slight decrease with increasing frequency (Figure 5). The NPS shows a strong dependency on KAD values as shown in Figures 6a to 6c. The highest NPS values were observed at the highest voltage as shown in Figure 6), as other authors have observed. ${ }^{35}$

The rapid decrease of the DQE with increasing spatial frequency is related to the shape of the MTF with a constant value of the NPS at frequencies above $1 \mathrm{lp} / \mathrm{mm}$ (Figures 7 and 8). Figure 7 shows a slight directional dependency of the DQE
(84 $\mu$ Gy KAD value covers the clinical level of KAD for the presented exposure). The DQE also shows a strong dependence on the KAD value as shown in Figures $\mathbf{8 a}$ to $\mathbf{8 c}$, as previously demonstrated by García-Mollá et al. ${ }^{13}$ and is independent of the tube voltage as shown in Figure 8d.

\section{Conclusions}

New software was developed to quantitatively assess the image detector in a digital mammography system. Using this software, it is possible to calculate various physical parameters such as the STP, MTF, NPS, and DQE. It may also be possible to develop this software to calculate the effective detective quantum efficiency (eDQE) ${ }^{36-40}$ which extends the DQE to include other system parameters such as focus blurring and scatter rejection systems.

In this study, the new software was used successfully for a preliminary analysis of image quality parameters for the detector in a Siemens Mammomat Inspiration.

DQE only describes the detector performance and is used mainly to compare mammography systems with different detector types or to assess how a detector in the same system changes over time. It is possible to use $\mathrm{DQE}$ for other purposes such as to estimate AEC efficiency in mammography system. ${ }^{41}$

Further studies are now under way to investigate eDQE in a number of mammography systems.

\section{References}

1. Narodowy Program Zwalczania Chorób Nowotworowych. http://profilaktykaraka.coi.waw.pl/, access: February 2020 [in Polish]

2. Didkowska J, Wojciechowska U. Zachorowania i zgony na nowotwory złośliwe w Polsce. Krajowy Rejestr Nowotworów, Narodowy Instytut Onkologii im. Marii Skłodowskiej-Curie - Państwowy Instytut Badawczy. http://onkologia.org.pl/k/epidemiologia/, access: April 2020 [in Polish]

3. Dz.U. 2017 poz. 884. Obwieszczenie Ministra Zdrowia z dnia 3 kwietnia 2017 r. w sprawie ogłoszenia jednolitego tekstu rozporządzenia Ministra Zdrowia w sprawie warunków bezpiecznego stosowania promieniowania jonizującego dla wszystkich rodzajów ekspozycji medycznej [in Polish]

4. American College of Radiology. Mammography Quality Control Manual. 1999

5. Huda W, Sajewicz AM, Ogden KM, Scalzetti EM, Dance DR. How Good Is the ACR Accreditation Phantom for Assessing Image Quality in Digital Mammography. Acad Radiol. 2002;9(7):764-772. https://doi.org/10.1016/S1076-6332(03)80345-8

6. Fabiszewska E, Grabska I, Pasicz K. The threshold contrast thickness evaluated with different CDMAM phantoms and software. Nukleonika. 2016;61(1):53-59. https://doi.org/10.1515/nuka-2016-0004

7. Fujita H, Tsai DY, Itoh T, et al. A simple method for determining the modulation transfer function in digital radiography. IEEE Trans Med Imaging. 1992;11(1):34-39. https://doi.org/10.1109/42.126908

8. Hoheisel M, Batz L, Mertelmeier T, Giersch J, Korn A. Modulation transfer function of a selenium-based digital mammography system. IEEE Symposium Conference Record Nuclear Science 2004, Rome, 2004;6:3589-3593. https://doi.org/ 10.1109/NSSMIC.2004.1466660

9. Carton AK, Vandenbroucke D, Struye L, et al. Validation of MTF measurement for digital mammography quality control. Med Phys. 2005;32(6):1684-1695. https://doi.org/10.1118/1.1921667

10. Samei E, Ranger NT, Dobbins JT 3rd, Chen Y. Intercomparison of methods for image quality characterization. I. Modulation transfer function. Med Phys. 2006;33(5):1454-1465. https://doi.org/10.1118/1.2188816 
11. Narváez M, Graffigna JP, Gomez ME, Romo R. Application of Oversampling to obtain the MTF of Digital Radiology Equipment. J Phys: Conf Ser. 2016;705:012057. https://doi.org/10.1088/1742-6596/705/1/012057

12. Williams MB, Mangiafico PA, Simoni PU. Noise power spectra of images from digital mammography detectors. Med Phys. 1999;26:1279-1293. https://doi.org/10.1118/1.598623

13. García-Mollá R, Linares R, Ayala R. Study of DQE dependence with beam quality on GE Essential mammography flat panel. Journal of Applied Clinical Medical Physics. 2011;12(1). https://doi.org/10.1120/jacmp.v12i1.3176

14. Ortenzia O, D'Alessio A, Noferini L, Ghetti C. Characterization of two CT systems using a channelized hotelling observer and NPS metric. Rad Prot Dos. 2020;189(2):224-233. https://doi.org/10.1093/rpd/ncaa034

15. Dobbins JT 3rd, Ergun DL, Rutz L, Hinshaw DA, Blume H. Clark DC, DQE(f) of four generations of computed radiography acquisition devices. Med Phys. 1995;22:1581-1593. https://doi.org/10.1118/1.597627

16. Samei E, Flynn MJ. An experimental comparison of detector performance for direct and indirect digital radiography systems. Med Phys. 2003;30(4):608-622. https://doi.org/10.1118/1.1561285

17. Marshall NW. Early experience in the use of quantitative image quality measurements for the quality assurance of full field digital mammography x-ray systems. Phys Med Biol. 2007;52:5545. https://doi.org/10.1088/0031-9155/52/18/006

18. Marshall NW. Detective quantum efficiency measured as a function of energy for two full-field digital mammography systems. Phys. Med. Biol. 2009; 54 2845, https://doi.org/10.1088/0031-9155/54/9/017

19. Samei E, Murphy S, Christianson, O. DQE of wireless digital detectors: Comparative performance with differing filtration schemes. Med Phys. 2013;40:081910. https://doi.org/10.1118/1.4813298

20. Marshall NW, van Ongeval C, Bosmans H. Performance evaluation of a retrofit digital detector-based mammography system. Phys Med. 2016;32(2):312-322. https://doi.org/10.1016/j.ejmp.2016.01.002

21. Borg M. Application of the European Protocol in the evaluation of digital mammography units with tungsten target tubes. Rad Prot Dos. 2019;184(4):507-518. https://doi.org/10.1093/rpd/ncz044

22. International Electrotechnical Commission. Medical electrical equipment - Characteristics of digital X-ray imaging devices - Part 1-2: Determination of the detective quantum efficiency - Detectors used in mammography. IEC 62220-1-2:2007

23. Williams L. The Optical Transfer Function of Imaging Systems. Institute of Physics. Bristol. 1999

24. Viallefont-Robinet F, Helder D, Fraisse R, et alS. Comparison of MTF measurements using edge method: towards reference data set. Opt Express. 2018;26:33625-33648. https://doi.org/10.1364/OE.26.033625

25. Greer PB, Van Doorn T. Evaluation of an algorithm for the assessment of the MTF using an edge method. Med Phys. 2000;27:20482059. https://doi.org/10.1118/1.1288682

26. Dobbins JT 3rd, Samei E, Ranger NT, Chen Y. Intercomparison of methods for image quality characterization. II. Noise power spectrum. Med Phys. 2006;33(5):1466-1475. https://doi.org/10.1118/1.2188819

27. Siemens Healthcare GmbH. Online tool for the simulation of X-ray Spectra. https://www.oem-products.siemens-healthineers.com/xray-spectra-simulation. access: april 2020

28. Joint Committee for Guides in Metrology. Evaluation of the measurement data - Guide to the expression of uncertainty in measurement (GUM), 2008

29. Buhr E, Günther-Kohfahl S, Neitzel U. Accuracy of a simple method for deriving the presampled modulation transfer function of a digital radiographic system from an edge image. Med Phys. 2003;30:2323-31. https://doi.org/10.1118/1.1598673

30. Illers H, Buhr E, Hoeschen C. Measurement of the detective quantum efficiency (DQE) of digital X-ray detectors according to the novel standard IEC 62220-1. Rad Prot Dos. 2005;114:39-44. https://doi.org/10.1093/rpd/nch507

31. Monnin P, Gutierrez D, Bulling S, Guntern D, Verdun FR. A comparison of the performance of digital mammography systems. Med Phys. 2007;34(3):906-914. https://doi.org/10.1118/1.2432072

32. Oborska - Kumaszyńska D, Wiśniewska-Kubka S. Ocena ilościowa parametrów cyfrowych detektorów radiologicznych obrazowania diagnostycznego - cz.2. Inżynier i Fizyk Medyczny. 2013;2(1):25-31.

33. Oberhofer N, Fracchetti A, Nassivera E, Valentini A, Moroder E. Comparison of Two Novel FFDM Systems with Different a-Se Detector Technology: Physical Characterization and Phantom Contrast Detail Evaluation in Clinical Conditions. In: Martí J., Oliver A., Freixenet J., Martí R. (eds) Digital Mammography. IWDM 2010. Lecture Notes in Computer Science, vol 6136. Springer, Berlin, Heidelberg. https://doi.org/10.1007/978-3-642-13666-5_62

34. Hoheisel M, Batz L, Mertelmeier T, Giersch J, Korn A. Modulation transfer function of a selenium-based digital mammography system. IEEE Transactions on Nuclear Science. 2006;53(3):1118-1122. https://doi.org/10.1109/TNS.2006.874953

35. Greiter MB, Hoeschen Ch. Mobile measurement setup according to IEC 62220-1-2 for DQE determination on digital mammography systems. Proc SPIE 7622, Medical Imaging 2010: Physics of Medical Imaging, 76224P. https://doi.org/10.1117/12.844196 
36. Samei E, Ranger N, Mackenzie A, Honey I, Dobbins J, Ravin C, Detector or System? Extending the Concept of Detective Quantum Efficiency to Characterize the Performance of Digital Radiographic Imaging Systems. Radiology. 2009;249:926-37. https://doi.org/10.1148/radiol.2492071734

37. Samei E, Ranger NT, MacKenzie A, Honey ID, Dobbins JT 3rd, Ravin CE. Effective DQE (eDQE) and speed of digital radiographic systems: an experimental methodology. Med Phys. 2009;36(8):3806-17. https://doi.org/10.1088/1361-6560/aaa307

38. Salvagnini E, Bosmans H, Struelens L, Marshall NW, Effective detective quantum efficiency (eDQE) and effective noise equivalent quanta (eNEQ) for system optimization purposes in digital mammography. Proc. SPIE 8313, Medical Imaging 2012: Physics of Medical Imaging, 83130H. https://doi.org/10.1117/12.911193

39. Wood TJ, Moore CS, Saunderson JR, Beavis AW, Measurement of effective detective quantum efficiency for a photon counting scanning mammography system and comparison with two flat panel full-field digital mammography systems. Phys Med Biol. 2018;39(2):025025. https://doi.org/10.1088/1361-6560/aaa307

40. Bor D, Guven A, Yusuf AR, et al. A modified formulation of eDQE for digital radiographic imaging. Rad Phys Chem. 2019;156:614. https://doi.org/10.1016/j.radphyschem.2018.10.010

41. Fabiszewska E, Wysocka-Rabin A, Dobrzyńska M, Skrzyński W, Pasicz K. Application of DQE for quantitative assessment of detectors to estimate AEC efficiency in digital mammography. Pol J Med Phys Eng. 2021;27(1):51-56. https://doi.org/10.2478/pjmpe2021-0007 